\title{
O TRIBUNAL DA INQUISIÇÃO EM PORTUGAL*
}

Anita Novinsky(1)

\section{A instituição do Tribunal da Inquisição em Portugal foi obra de um jogo entre os interesses da Igreja e os do Estado}

Há 450 anos, no dia 23 de maio de 1536, uma Bula do papa Paulo III instituiu em Portugal o Tribunal do Santo Ofício da Inquisição. Na passagem dos quinhentos anos do estabelecimento desse mesmo Tribunal na Espanha, realizaram-se nesse país (Cuencas, Toledo, Madri) e no estrangeiro (Nova lorque, Copenhagem) diversos congressos, simpósios, encontros, exposições, cujos trabalhos e catálogos já foram publicados. Em Portugal e no Brasil sentiu-se a necessidade de lembrar também esse fenômeno histórico, de tão largas conseqüências para o Reino como para a colônia brasileira, e as universidades de São Paulo e de Lisboa, conjuntamente com as sociedades Portuguesa e Brasileira de Estudos do Século XVIII, programaram um congresso internacional, a realizar-se em duas fases - fevereiro de 1987 em Lisboa, e em maio de 1987 em São Paulo, acompanhado de diversos eventos paralelos. Para essas reuniões científicas foi obtido o apoio de entidades oficiais, tanto no Brasil quanto em Portugal. É interessante, pois, lembrarmos, mesmo que suscintamente, a longa luta que se travou entre o rei de Portugal, d. João III, e a Cúria Romana, para se introduzir nas nações ibéricas um Tribunal do Santo Ofício da Inquisição, cujo radicalismo e técnicas empregadas absolutamente não condiziam com as tradições de Espanha e Portugal. O Estado adotou, então, uma política de rigoroso controle social, utilizando como ideologia a religião católica.

D. João teve que empregar toda sorte de manobras políticas para alcançar os objetivos que Ihe permitiriam centralizar o poder político e religioso nas mãos da Coroa. Lutou com o Vaticano trinta anos, antes que obtivesse de Roma a Bula definitiva para estabelecer o Tribunal da Inquisição em Portugal. Durante todo esse período de negociações, a balança a favor ou contra o estabelecimento do Tribunal se inclinava conforme o peso das ofertas dos ricos judeus mercadores de Lisboa.

(1) Doutora em História, é professora de História do Brasil na Universidade de São Paulo, e autora, entre outros, do livro "A Inquisição" (Ed. Brasiliense).

Texto reproduzido, com permissão da autora, do Suplemento Folhetim no $536-$ Fotha de S. Paulo, 15 de maio de 1987. 
Para certos autores modernos, a existência da Inquisição foi uma das causas que levou à decadência das nações peninsulares, mas preferimos repetir com o saudoso amigo e professor, Joaquim Barradas de Carvalho, que tão profundamente estudou a Renascença portuguesa, que o estabelecimento da Inquisição foi um sintoma de uma decadência já em curso.

A partir dessa data, a política, a cultura, a sociedade, desviam-se cada vez mais dos rumos que tomaram as nações européias, merguIhando Portugal num obscurantismo tão profundo que, com exceção de alguns periodos, continuou até a Revolução de 25 de abril de 1975.

A necessidade de repensarmos o fenômeno da Inquisição em geral torna-se ainda mais premente se prestarmos atenção às tendências da historiografia contemporânea, que, mesmo procurando dar a seus trabalhos um cunho científico e de objetividade, tenta minimizar a sua ação, tanto em termos político-econômicos como em violência e crueldade. Um artigo publicado recentemente no suplemento Cultura, de $O$ Estado de S. Paulo (16/3/86), traduzido da revista francesa Commentaire com o titulo "A Outra Face da Inquisição" de autoria de John Tedeschi, é um exemplo dessa tendência.

O Tribunal do Santo Ofício da Inquisição, em Portugal, diferentemente dos tribunais medievais, foi introduzido exclusivamente para fiscalizar e punir os descendentes de judeus que haviam sido convertidos à força ao catolicismo, e sob suspeita de praticar a religião judaica. Foi gradativa a ampliação de seus objetivos até abarcar diversos tipos de comportamento e crenças. As heresias em matéria de fé juntaram-se feitiçaria, bruxarias, sodomia, bigamia, blasfêmias, proposições, desacatos e problemas diversos de sexualidade.

Mas tanto em Portugal quanto no Brasil, esses crimes menores, como são chamados pelos historiadores espanhóis, foram insignificantes em comparação com os crime contra fé. Não me refiro aqui à questão dos números, mas à gravidade da heresia judaica e à importância que os inquisidores lhe conferiam. Apenas para dar um exemplo, a sentença que recebiam os cristãos-novos acusados de judaísmo era, na maior parte das vezes, "carcere e Hábito Penitencial Perpétuo", enquanto os cristãos-velhos recebiam penas brandas. E só cristãos-novos no Brasil tiveram sentença de morte na fogueira.

\section{Igreja $\times$ Estado}

Tem-se perquntado muitas vezes qual foi o papel de Roma no desenrolar desse processo. Seria difícil responder em poucas linhas, visto que a atitude do clero católico variou conforme o tempo e o 
espaço. No momento de seu estabelecimento, porém, os diversos papas que acompanharam as negociações com Portugal não apoiaram facilmente os ideais do monarca português, e não foram também membros da Igreja Católica os que clara e abertamente se expressaram a favor da política religiosa de d. João III. O papa Clemente VII, por exemplo, apesar de sua má fama, tudo fez para favorecer os judeus perseguidos, assim como também os bispos Diego Pinheiro, de Funchal, e Fernando Coutinho, de Silves. Era unânime a opinião desses prelados de que não podiam ser considerados súditos da Igreja aqueles que foram forçados a aceitar uma fé imposta através da violência e que, ainda que em matéria de fé, não devia haver coerção. Ante o clima de terror que se lançou sobre a sociedade portuguesa, principalmente sobre os descendentes de judeus, ameaçados continuamente de serem presos e acusados de judaísmo, o papa Clemente VII emitiu um "Breve de Perdão Geral aos Cristãos-Novos" 17 de abril de 1533). Tomando conhecimento desse "Breve" d. João III, enfurecido, tentou comprar a sua anulação através de seu embaixador em Roma.

O papa, contudo, manteve-se inabalável. Ao contrário, encaminhou o "Breve" para avaliação dos célebres juristas da Universidade de Bolonha, e tanto Valo como o futuro cardeal Parisio emitiram dois relatórios nos quais apoiavam e defendiam os cristãos-novos, e aprovavam o perdão papal. Representantes portugueses tentaram argumentar, chegando mesmo a desacreditar o papa, alegando que se Sua Santidade não considerava os batizados à força cristãos, mas judeus, com que direito os empregava em cargos eclesiásticos, e como podia, em sua posição apostólica, absolvê-los (Kayserling, 1971, p. 169). O próprio imperador Carlos $V$ tentou intervir em favor de seu cunhado d. João, mas não conseguiu remover a decisão de Clemente, nem a opinião da maioria dos cardeais. A corte de Roma manifestava-se então totalmente favorável aos cristãos-novos.

D. João III, membros da Igreja aliados a ele e nobres, não deram ouvidos nem às ordens do papa, nem às suas Bulas nem aos seus Breves, e os portugueses foram gradativamente condicionados pela propaganda oficial. O rei colocou sua máquina em funcionamento e organizou a sua inquisição nos moldes espanhóis.

O conflito entre a hierarquia eclesiástica e os representantes do Estado não é um fenômeno exclusivo de nossos dias.

D. João, recusando-se a obedecer ao papa, foi ameaçado de excomunhão, e teve de esperar até a morte de Clemente para estabelecer o Tribunal do Santo Ofício em Portugal e colocar em funcionamento seu aparelho burocrático, que nublou todo o império português du- 
rante mais de dois séculos. Ainda no leito de morte, Clemente VII insistiu para que se publicasse a Bula de Perdão aos cristãos-novos judaizantes perseguidos em Portugal e, segundo Kayserling, esse foi o mais belo monumento que ergueu para si próprio (Kayserling, 1971, p. 167).

Paulo III foi empossado em 13 de outubro de 1534 e inicialmente também se opôs ao estabelecimento do Tribunal. 0 conflito entre a corte portuguesa e o Vaticano acirrou-se ainda mais. De um lado, o imperador Carlos $V$, na própria carta de congratulações que enviou ao novo papa, pediu-Ihe que suspendesse a Bula de Perdão concedida por seu antecessor aos suspeitos de judaísmo e, de outro lado, agentes portugueses trabalhavam em Roma para convencer Paulo III da necessidade do Tribunal.

O papa convocou uma comissão, constituída pelos cardeais Jeronimo Ghinucci e Jacobo Dimonetta, e as conversações estenderam-se durante semanas sem que chegassem a um acordo. $O$ cardeal Ghinucci, que havia sido embaixador em Castela, perfeitamente consciente das crueldades operadas pela Inquisição espanhola, recusou-se a aceitar os argumentos do representante português, chegando mesmo a defender os cripto-judeus no livro Auditor Camerae est Suspectissimus in Ista Causa tum quia Fuit Advocatus Praedictis Conversis, tum quia Scripsit pro Eis et Consilium Ecit Stampare (Kayserling, 1971, p. 172 nt. 13).

Ante a ordem expressa de Paulo III para que a Bula de Perdão de Clemente VII fosse publicada, os agentes portugueses, assim como o próprio rei, iniciaram toda sorte de difamações contra os mais honrados homens da Cúria, entre eles o próprio Ghinucci. D. João III, querendo vingar-se, utilizou toda sorte de intrigas contra o papa, para provar a legalidade de seus propósitos. Mandou ainda prender um certo número de cristãos-novos, negando-se a obedecer às ordens do mais alto dignatário da Igreja.

A Bula de Perdão, contudo, já tinha sido publicada em todo o país, mas sem que o rei dela tomasse conhecimento. Paulo III, enfurecido ante as difamações, exigiu que a Bula fosse obedecida rigorosamente e procurou favorecer os perseguidos, exigindo que fosse anulada a lei de 14 de junho de 1532, que proibia a saída dos cristãos-novos de Portugal. A persistente atitude do rei de Portugal, de impedir os cristãos-novos de deixarem o país, foi continuamente combatida pelo Sumo Pontífice e por clérigos da Cúria. Mas d. João III tinha um alvo claro: perseguir os cristãos-novos e obrigá-los a permanecer no país. 


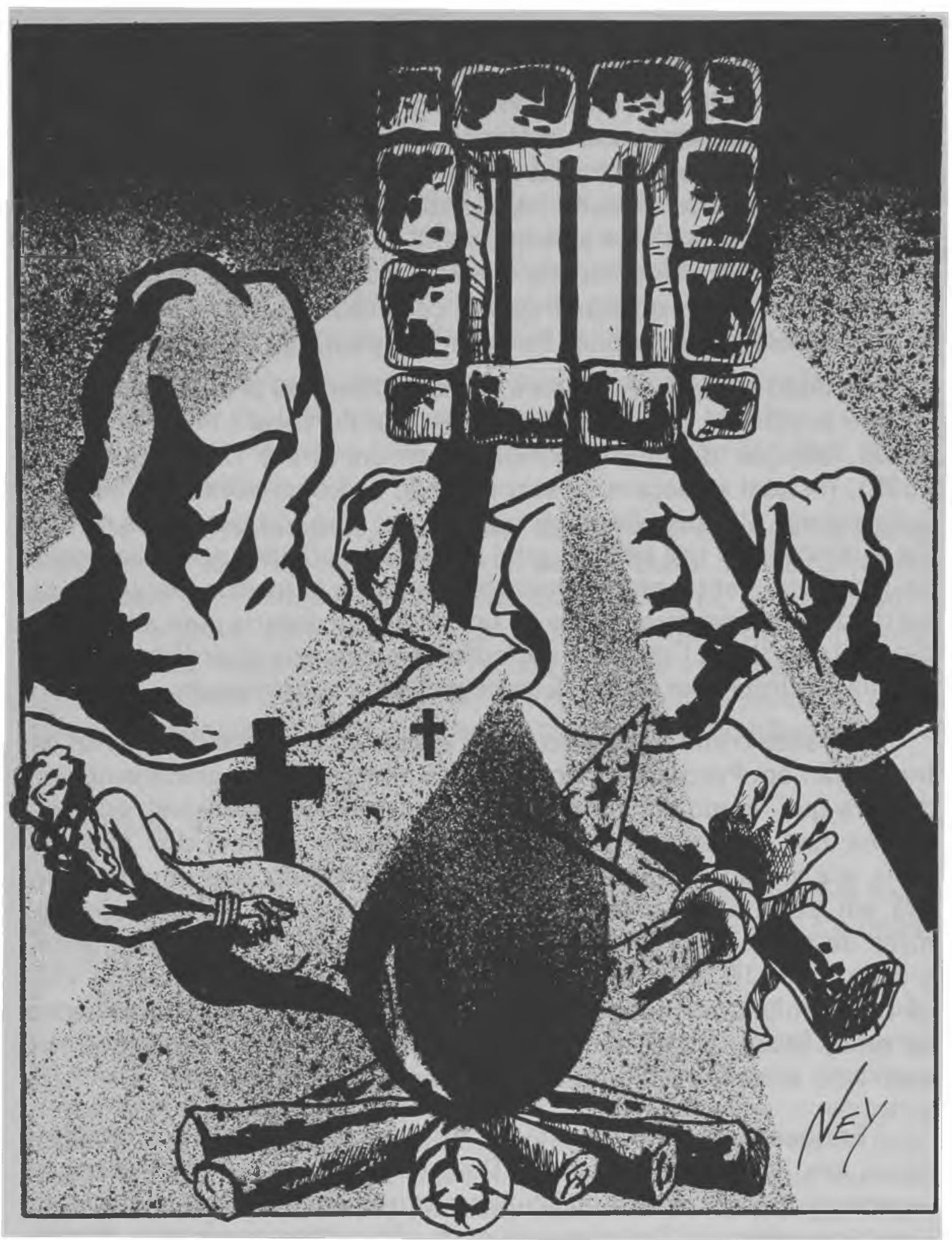

Ovos de ouro

Os portugueses, por sua vez, tentaram todos os meios para impedir que o Tribunal fosse estabelecido em sua pátria. Dois cristãos-novos, Tomás Serrão e Manuel Mendes, dirigiram-se a Roma para representar seus correligionários, e ofereceram ao papa uma recompensa de trinta mil ducados, caso proibisse o estabelecimento da Inquisição 
como instituição autônoma. Pediram ainda que todos os crimes relacionados com questões de fé fossem julgados por tribunais civis, que os processos só fossem aceitos no prazo de vinte dias após o delito, que ao preso fossem comunicadas imediatamente as razões da acusação, que não se aceitassem testemunhos de escravos, desclassificados, cúmplices, que não fossem instaurados processos contra falecidos, que se permitisse aos réus a livre escolha de advogados e procuradores assim como o direito de apelar a Roma, que o confisco de bens fosse suspenso e que em qualquer época, com todas as suas posses, tivessem liberdade de abandonar Portugal (Kayserling, 1971, p. 174-75).

D. João III, cada vez mais indignado, renovou propositalmente a lei que proibia os cristãos-novos saírem de Portugal (14 de junho de 1532), ao que o papa respondeu com um Breve (20 de julho de 1535), no qual ameaçava de excomunhão todos aqueles que the desobedecessem. Mas propôs ao rei um acordo: caso soltasse todos os presos e concedesse um perdão geral a todos os cristãos-novos acusados de judaísmo, tanto os encarcerados como os suspeitos, deixando-os partir de Portugal num prazo de um ano, concordaria com a introdução da Inquisição. Conceder aos cristãos-novos esta liberdade não respondia aos interesses do rei. $E$ as negociações continuaram.

Durante trinta anos discutiu-se a questão do estabelecimento da Inquisição em Portugal e a liberdade de emigração dos cristãos-novos, demora que, como diz Poliakov, é facilmente compreensivel, pois nenhuma das partes em causa desejava matar a galinha dos ovos de ouro, e a ameaça de uma Inquisição, bem mais do que uma Inquisição em exercício, permitia fazer cantar os ricos e industriosos homens de negócios (Poliakov, 1984, p. 201). Insultado publicamente, o papa Paulo III promulgou uma Bula semelhante à de Clemente VII, na qual proibia qualquer condenação de cristãos-novos, independente de sexo, idade, posição, classe, e declarando livres todos que já haviam sido acusados de judaísmo (Kayserling, 1971, p. 176).

Enquanto os altos dignatários discutiam, a situação dos cristãosnovos em Portugal deteriorava. De ambos os lados, exigia-se continuamente que fornecessem fabulosas somas em dinheiro, e chegaram a ser ameaçados de um massacre caso não aumentassem seus donativos. Os banqueiros pertencentes à família Mendes ofereceram cinco mil escudos através dos agentes portugueses em Roma, mas assim que o rei tomou conhecimento dessa soma, imediatamente fez oferta semelhante. Carlos $V$ que então se encontrava em Nápoles, intercedeu novamente junto a Paulo III, e desta vez acabou vencendo o mais forte. $O$ estabelecimento da Inquisição foi autorizado.

Parece, contudo, que a decisão tomada pelo papa não o satisfez, 
e seus atos mostram que continuou inclinado à causa dos judeus portugueses. Estes contavam em Roma com amigos que o convenceram de que a Bula tinha sido promulgada de maneira ilegal e contra todos os direitos dos povos e dos homens, e que devia ser anulada. Os cristãos-novos elaboraram então um Memorial, no qual expõem os horrores do Tribunal e a maneira arbitrária com que eram tratados na própria pátria, pedindo que os deixassem sair e buscar abrigo "entre povos menos cruéis" Esse Memorial só foi descoberto no século XIX (Kayserling, 1971, p. 183). Milhares de processos que existem no Arquivo Nacional da Torre do Tombo comprovam sua veracidade.

Paulo III tinha conhecimento do que se passava em Portugal e alimentava por $d$. João enorme desprezo. Não lhe agradou a nomeação do cardeal Henrique para inquisidor-mor e tudo fez para proteger os cristãos-novos.

Os homens da Igreja, em Roma, também continuavam a alertar o papa sobre as atrocidades praticadas pelo Tribunal, e este renovou a nunciatura em Portugal, escolhendo Luiz Lipomano, bispo e coadjutor de Bergamo, para ocupar o cargo. D. João mostrou os inconvenientes dessa nova nunciatura e mandou que se informasse ao papa sobre as heresias que se alastravam pelo país, além do judaísmo e dos surtos messiânicos, e sobre o perigo de contágio dos cristãos-velhos.

\section{Auto-de-fé}

Enquanto isso, a Inquisição se fortalecia. Os autos-de-fé sucediam-se, e foram condenados portugueses em Lisboa, Evora, Coimbra, Lamego, Tomar e Porto. Mui tos morreram queimados.

Em Roma nunca houve segredo sobre as intenções de d. João III, e tinha-se conhecimento de que a autorização do estabelecimento da Inquisição fora concedida por razões políticas. 0 papa procurou tomar uma série de medidas para alterar a Bula e ameaçou novamente o rei de excomunhão caso não deixasse os cristãos-novos sair do país. Mandou dizer-lhe ainda que tinham informações, através de seu núncio em Portugal, Hieronimo Ricenati Capodiferro, de que não foram razões de fé que o levaram a se interessar pela instituição do Tribunal, mas seu desejo de apoderar-se das riquezas dos cristãos-novos. 0 próprio Capodiferro acumulou enormes riquezas, ajudando-os a fugir. Quando um navio que transportava seus bens naufragou, o embaixador português comentou satisfeito: "Não é sem razão que esse barco, carregado de despojos do sangue de Nosso Senhor Jesus e dos presentes ofertados por seus inimigos, socobrou no mar" (Herculano, 1975, tomo 2, p. 255). 
Afinal a Cúria Romana acabou sendo comprada por dinheiro. 0 cardeal Farnese recebeu em pagamento o bispado de Viseu, além de uma renda anual de cerca de vinte mil ducados. O cardeal Santiquatro, velho amigo do rei, obteve uma pensão anual de mil e quinhentos cruzados e o cardeal Crescentiis uma pensão de mil cruzados. Ninguém trabalhou gratuitamente (Kayserling, 1971). Os portugueses cristãos-novos não conseguiram comprar a piedade de Roma e viveram sob a ameaça da Inquisição durante 285 anos. O Tribunal foi abolido em 1821, mas seus efeitos ainda se fazem sentir em Portugal - como no Brasil - em sua história, suas condições materiais de vida e sua mentalidade. 0 10 Congresso Luso-Brasileiro, propondo uma abordagem científica e crítica da Inquisição, inicia uma nova fase na historiografia contemporânea.

\section{Referências Bibliográficas}

1 - HERCULANO, A. História da origem e estabelecimento da Inquisição em Portugal. Lisboa, Bertrand, 1975.

2 - KAYSERLING, M. História dos judeus em Portugal. Trad. de Gabriela Borchard e Anita Novinsky. São Paulo, Pioneira, 1971.

3 - POLIAKOV, Leon. De Maomé aos Marranos. São Paulo, Perspectiva, 1984.

\section{FICHA CATALOGRÁFICA}

NOVINSKY A. O tribunal da Inquisição em Portugal. Revista da Universidade de São Paulo. São Paulo, (5) : 91-98, jun. 1987. 